\title{
Un análisis del discurso de Rodrigo Londoño Echeverri, Timochenko, el 1 de septiembre de 2017 en la Plaza de Bolívar
}

\author{
An analysis of the speech of Rodrigo Londoño Echeverri, Timochenko, on \\ September 1, 2017 in the Plaza de Bolívar
}

\author{
Sergio Roncallo-Dow* \\ Juan David Cárdenas Ruiz* \\ María Catalina Cruz-González ${ }^{* * *}$
}

\begin{abstract}
Resumen: Este trabajo propone un análisis del discurso de Rodrigo Londoño Echeverri, Timochenko, el 1 de septiembre de 2017 en la Plaza de Bolívar en Bogotá. En un primer momento presentamos los antecedentes del conflicto armado haciendo énfasis en la confrontación con las Farc para, luego, evidenciar el contexto en el que se da la intervención de Londoño. Posteriormente exponemos la metodología que utilizaremos y que nos permitirá construir nuestra matriz de análisis. El análisis hecho evidencia que dentro del discurso pueden inferirse vectores de inclusión/exclusión que dan luces sobre lo que ha sido el discurso sobre la paz desde el inicio de los Diálogos de La Habana; en ese sentido el discurso de Londoño se presenta como una síntesis de un proceso ya polarizado y que, bajo la apariencia de un llamado conciliador tendría un subtexto de exclusión y una consecuente repolarización.
\end{abstract}

Palabras Clave: Farc, Conflicto armado, Proceso de Paz, Colombia, Timochenko, análisis de discurso

Abstract: This paper proposes an analysis of the speech of Rodrigo Londoño Echeverri, Timochenko, on September 1, 2017 at the Plaza de Bolívar in Bogotá. Initially, we present the antecedents of the armed conflict emphasizing the confrontation with the FARC and then show the context in which Londoño's

\footnotetext{
* Colombiano. Autor principal. Es Doctor en Filosofía y Magíster en Comunicación de la Universidad Javeriana y Filósofo de la Universidad de Los Andes. Es Profesor Asociado de la Universidad de La Sabana. Correo electrónico: sergiord@unisabana.edu.co

** Colombiano. Coautor. Es Magíster en Estudios Políticos y Politólogo de la Universidad Nacional de Colombia y Especialista en Comunicación Pública y Mercadeo Político de la Pontificia Universidad Javeriana. Es Profesor Asistente de la Universidad de La Sabana. Correo electrónico: juancar@unisabana.edu.co

*** Colombiana. Coautora. Es Comunicadora Audiovisual y Multimedios y Profesora Junior en formación de la Universidad de La Sabana. Correo electrónico: maria.cruz3@unisabana.edu.co
} 
intervention takes place. Later we expose the methodology that we will use and that will allow us to build our analysis matrix. The analysis made evidences that within the discourse, inclusion / exclusion vectors can be inferred that give light on what the discourse on peace has been since the beginning of the Havana Dialogues; In that sense, Londoño's speech is presented as a synthesis of an already polarized process that, under the appearance of a conciliatory call, would have a subtext of exclusion and a consequent re-polarization.

Key Words: Farc, Armed Conflict, Peace Process, Colombia, Timochenko, discourse analysis

Recibido: 3 septiembre 2019 Aceptado: 28 octubre 2019

"Adiós a las armas, adiós a la guerra, bienvenida la paz"

Timochenko

“Necesitamos éticas del cuidado, éticas de la creatividad emotiva, afectiva, o si no, estamos condenados" Sergio de Zubiría

"Solo un pueblo escéptico sobre la fiesta de la guerra, maduro para el conflicto, es un pueblo maduro para la paz".

Estanislao Zuleta

\section{Introducción}

El trabajo parte de una matriz de elaboración propia que nos permitió trazar tres grandes categorías para el análisis: la idea de país, la noción de partido político y la idea misma de acuerdo. De igual manera, el trabajo dedica un aparte al análisis del rol de los medios de comunicación en la construcción de sentidos colectivos y al rol que estos juegan dentro del discurso de Londoño Echeverri. El análisis de discurso funciona para nosotros en este caso en la medida en que nos permite comprender los modos en los que el poder se articula bajo las formas, aparentemente asépticas del lenguaje; el poder funciona a lo largo y ancho de 
las estrategias discursivas de los diversos actores sociales y desde allí se crean agendas y se moldean las formas de lo común ${ }^{1}$.

Si bien partimos de una pieza relativamente $\operatorname{corta}^{2}$, su análisis es de importancia capital en la medida en que se trata de lo que podríamos llamar la enunciación de ingreso de las Farc a la vida civil y que, por lo tanto, da los derroteros para pensar lo que será su actuar y su rol en la vida política de Colombia.

El discurso de Londoño ha sido abordado a partir de la idea de la intencionalidad inherente a todo acto de habla y llevamos este punto a la idea del ejercicio político presente en el lenguaje. Como lo muestran González et al. ${ }^{3}$ la comunicación es el acto constituyente de lo social y está tamizada por dinámicas de poder. De ahí que hayamos elaborado (como se verá en la metodología) ciertas ideas como las de "vectores de inclusión/exclusión” y "subtexto de exclusión" (que apuntan al quien y al cómo del sujeto que modela el discurso) que enfatizan lo que hemos llamaremos lo "no dicho", una exteriorirdad que no es aprehensible en el texto mismo, hemos buscado aquello que el texto calla; "el estudio no se refiere al texto en sí, a algo que esté dentro del texto, sino a algo que está fuera de él, en un plano distinto, es decir, a lo que el texto significa, a su sentido y significado". ${ }^{4}$ Creemos que estas ideas enfatizan la idea de la lucha presente en el acto comunicativo y que un análisis del lenguaje como una forma de práctica social nos permite estudiar los modos en que la dominación se (re)produce y se resiste con los discursos ${ }^{5}$.

\section{Contexto general del conflicto en Colombia}

El conflicto armado interno tiene diversos orígenes: la violencia bipartidista, la distribución de la tierra, la reducida participación política, entre otros. Al ser estos factores a su vez el origen de las Farc, se relaciona el surgimiento de esta guerrilla con el origen del conflicto armado; en un al principio eran grupos de autodefensa y a partir de la cuarta y quinta conferencia, 1974 y 1978, deciden que tienen el suficiente poder militar para emprender el ejercicio de la toma del poder.

Aparecen, de manera paralela, actores como el ELN, en 1964. En sus inicios las Farc hacen llamar Bloque Sur y en1966 las Farc son bautizadas con ese nombre y, en 1967, se crea el

\footnotetext{
1 Byung-Chul Han, Sobre el poder, Barcelona, Herder, 2016. Byung-Chul Han, Hegel y el poder. Un ensayo sobre la ambilidad. Barcelona, Herder, 2019.

2 Iván Gallo en Las 2 Orillas, "El día en que las Farc se tomaron la plaza de Bolívar", 02 de septiembre, 2017. Disponible en: https://www.las2orillas.co/dia-las-farc-se-tomaron-la-plaza-bolivar/ Revisado: 17 de junio de 2019

3 Manuel Ignacio González Bernal, Sergio Roncallo-Dow, Germán Arango Forero, Estudiar las audiencias. Tradiciones y perspectivas, Pamplona, Eunsa, 2018.

4 Miguel Martínez Miguélez, "Hermenéutica y análisis del discurso como método de investigación social”, PARADIGMA XXIII:12, Maracay, 2002, 1-13, p. 7.

${ }^{5}$ Norman Fairclough, Language and Power, London, Longman, 1989
} 
EPL. Sin embargo, en los años ochenta entraron en escena dos actores más del conflicto, uno que fue la respuesta a los movimientos guerrilleros, y el otro que posibilitó un escalamiento bélico del conflicto. Estos actores fueron el paramilitarismo y el narcotráfico ${ }^{6}$.

Como lo muestra Ronderos ${ }^{7}$, de la mano de Henry de Jesús Gómez y Ramón Isaza el paramilitarismo surgió en Puerto Boyacá ${ }^{8}$. Este movimiento en principio surgió como una respuesta de autodefensa por parte de ganaderos y campesinos a las conocidas "vacunas", cobros realizados por la guerrilla en su momento a diferentes grupos o individuos por trabajar o vivir en sus zonas de dominio, sin embargo, no tardaron en convertirse en ejércitos privados de narcotraficantes, que vigilaban las rutas del narcotráfico y protegían a los narcotraficantes de los ataques por parte de los diferentes grupos guerrilleros.

Por otro lado, las guerrillas no tardaron en recurrir al narcotráfico para sostenerse económicamente, por lo cual se sumó al secuestro y la extorsión como una manera de generar ingresos económicos. De este modo, al obtener dinero tan rápida y esporádicamente, los diferentes grupos armados lograron dotarse de mejor y mayor armamento así como una mayor exposición mediática y una más amplia participación en la agenda pública del país 9 .

Durante los años 80 y 90 el Estado colombiano realizó procesos de paz y negociaciones con los diferentes grupos armados, logrando las desmovilizaciones de varios grupos armados: Las guerrillas EPL, M-19, Quintín Lame, sectores del ELN y grupos de autodefensa, como los hombres de Fidel Castaño o los hombres de Gonzalo Rodríguez Gacha ${ }^{10}$.

De 1982 a 1986 el gobierno de Belisario Betancur tuvo una serie de negociaciones con las Farc, que lograron los acuerdos de La Uribe y la creación del partido político Unión Patriótica. Sin embargo, quienes conformaron este colectivo comenzaron a ser perseguidos y 4000 miembros de la Unión Patriótica fueron asesinados ${ }^{11}$. Esto llevó al fin de las negociaciones y a que quienes hicieron parte de la UP volvieran las montañas del país a retomar la lucha armada. Cabe aclarar que la Unión Patriótica agrupó diferentes sectores de

\footnotetext{
6 Jefferson Jaramillo Marín, Pasados y presentes de la violencia en Colombia. Estudios sobre las comisiones de investigación (1958-2011), Bogotá, Editorial Pontificia Universidad Javeriana, 2014, 27.

7 María Teresa Ronderos, Guerras recicladas. Una historia periodística del paramilitarismo en Colombia, Bogotá, Aguilar, 2014.

${ }^{8}$ Este es un punto inicial. En los años ochenta, el paramilitarismo tuvo tres vertientes: el MAS fruto del Cartel de Medellín y la fuerza pública (Antioquia, Magdalena Medio); una vertiente impulsada por Gonzalo Rodríguez Gacha (Autodefensas de Yacopí) en Puerto Boyacá (Magdalena Medio); aparecen también Los Castaño y los Tangueros, posteriormente Autodefensas Unidas de Córdoba y Urabá (Córdoba y Urabá).

${ }_{9}^{9}$ James J. Brittain. Revolutionary Social Change in Colombia: The Origin and Direction of the Farc-EP, New York, Pluto Press, 2010.

10 Luis Javier Orjuela Escobar, La sociedad colombiana en los años noventa: fragmentación, legitimidad y eficiencia, Bogotá, Universidad de Los Andes, 2005.

11 Julián Penagos-Carreño, "1984 Representaciones de las Farc en la prensa: guerrilla comunista o narcoguerrilla", Palabra Clave 18:1, Chía, 2015, 12-40.
} 
la sociedad, no solamente desmovilizados ni guerrilleros, sino políticos, líderes sindicales y comunitarios $^{12}$.

Hacia mediados de los años noventa las guerrillas de las Farc y el ELN mantenían la lucha armada de manera activa y constante y constituían el principal actor insurgente. Sin embargo, hacia 1997, grupos de autodefensas de todo el país deciden unirse bajo un mismo nombre y bajo un mismo mando, dejarían de existir las Autodefensas Campesinas del Magdalena medio, las Autodefensas Campesinas de Córdoba y el Urabá, entre otras, para llamarse Autodefensas Unidas de Colombia.

El surgimiento de un grupo de autodefensas organizado y unificado recrudeció el conflicto, por lo cual desde 1997 hasta 2005 (año de desmovilización de las AUC) los combates entre grupos guerrilleros y paramilitares se intensificaron, dejando como resultado masacres, muertes y miles de personas desplazadas.

En este panorama (mucho más complejo por la presencia de nuevos actores de corte para estatal), el presidente Andrés Pastrana (1998-2002) inició un nuevo proceso de paz con las Farc en 1999. El llamado proceso de negociación del Caguán duró tres años, en los cuales el gobierno entregó una zona de distensión a las Farc, y finalizó con el secuestro de las Farc a un avión de la Fuerza Aérea Colombiana. Durante los siguientes años el conflicto volvió a recrudecer hasta la administración posterior ${ }^{13}$. En 2002 el ex gobernador de Antioquia y creador de las Convivir, Álvaro Uribe Vélez, ganó las elecciones presidenciales con la promesa de acabar con las Farc por la vía militar. Esta idea se tradujo en la política de seguridad democrática, que consistía, esencialmente, en que el Estado y sus grupos militares debían fortalecer y ampliar la presencia y seguridad en todo el territorio, y que al mismo tiempo la sociedad civil estaba obligada a colaborar para obtener un éxito militar ${ }^{14}$.

Durante los ocho años de su gobierno Uribe logró dar algunos golpes a las Farc, el Estado volvió a muchos territorios dominados por la guerrilla y se dio la aparente desmovilización de las Autodefensas Unidas de Colombia en gran parte con el apoyo de aliados considerados estratégicos como Estados Unidos ${ }^{15}$.

Para las elecciones presidenciales de 2012, Álvaro Uribe no pudo aspirar a su segunda reelección y Juan Manual Santos su ex ministro de defensa, fue la cuota política que

\footnotetext{
12 Brittain, op. cit, 206.

${ }^{13}$ Leonel Narváez Gómez, "Twenty years of negotiating peace: A recipe of sticks and carrots”, Ellen Babbit (editora), Human Rights and Conflict Resolution in Context: Colombia, Sierra Leone, and Northern Ireland, Syracuse (New York), 2009, 46-69.

14 Juan Manuel Santos, La batalla por la paz. El largo camino para acabar con el conflicto con la guerrilla más antigua del mundo, Bogotá, Planeta, 2019.

15 Jairo Agudelo Taborda y Davide Riccardi, “La cooperación internacional para la paz en Colombia: los casos de Estados Unidos y de la Unión Europea (1998-2016)", Geopolítica(s). Revista de estudios sobre espacio y poder, 10:1, Madrid, 2019, 107-134.
} 
propuso para continuar la política de seguridad democrática y la lucha contra la guerrilla. Su popularidad y el apoyo de entonces, la muy fuerte maquinaria política del uribismo permitió a Santos ganar las elecciones de 2010 con amplia diferencia: en primera vuelta obtuvo el $46.8 \%$ de los votos y en segunda vuelta venció al candidato de centro Antanas Mockus con el $69.3 \%$ de los votos.

Sin embargo, en su segundo año de mandato, el gobierno de Juan Manuel Santos y las Farc iniciaron un nuevo proceso de paz, contrario a lo que muchos votantes, en su mayoría de derecha y extrema derecha pensaron. A fin de cuentas, Santos había llegado al poder enarbolando las banderas de la política de seguridad democrática de Uribe y la posibilidad de una salida agonística del conflicto fue interpretada como una traición. Con todo, es clave enfatizar aquí que el camino emprendido por Santos tenía un asidero fundamental en lo que yacía plasmado en el Plan Colombia (una acuerdo de cooperación bilateral entre Estados Unidos y Colombia concebido durante las administraciones Clinton y Pastrana) que, aunque en su primera fase llamada Plan para la paz, la prosperidad y el fortalecimiento del Estado, instaba al fortalecimiento de la fuerza pública en sus dos fases posteriores hacía énfasis en la idea del desarrollo social y la protección de los derechos humanos y la atención integral a la población desplazada por el conflicto ${ }^{16}$. Los puntos planteados en las fases dos y tres del Plan resultaban impensables e irrealizables en el marco de un conflicto armado tan crudo como el que había vivido Colombia durante las épocas de la política de seguridad democrática. La fase pública de negociaciones comenzó a finales de 2012 en Oslo, Noruega, para más tarde trasladar la mesa de negociaciones a La Habana, Cuba. Las Farc declararon un alto al fuego de dos meses por motivo de las conversaciones.

En 2013 se alcanzó un acuerdo entre la guerrilla y el Estado colombiano en la reforma de la tierra y ambas partes acordaron la importancia de la participación política. Los acuerdos poco a poco avanzaban y aunque la idea de ver a las Farc sentadas negociando cada vez era más aceptada por la sociedad civil, amplios sectores de la derecha seguían cuestionaban fuertemente las negociaciones de La Habana.

En este contexto, las elecciones presidenciales de 2014 tuvieron como centro de discusión la continuidad de los diálogos de paz. El enfrentamiento se dio, entonces, entre Juan Manuel Santos que enarbolaba su reelección en la búsqueda dialogada de la paz y Óscar Iván Zuluaga que representaba a las facciones de derecha más extrema y el regreso a la política de seguridad democrática. En la segunda vuelta Santos gana la presidencia apoyado por una buena parte de los sectores de izquierda.

\footnotetext{
16 Dirección de Justicia, Seguridad y Gobierno (DJSG) y Dirección de Seguimiento y Evaluación de Políticas Públicas (DSEPP), "Plan Colombia: Balance de los 15 años". Disponible en: https://sinergia.dnp.gov.co/Documentos\%20de\%20Interes/PLAN_COLOMBIA_Boletin_180216.pdf Revisado: 24 de octubre de 2019.
} 
Sin embargo, el secuestro al general Rubén Darío Alzate por parte de las Farc hizo que se suspendieran las conversaciones de paz. El general fue liberado y en diciembre de este año las Farc declaran un alto al fuego unilateral. En abril de 2015 las Farc asesinaron a once militares en Buenos Aires, Cauca. El gobierno colombiano reanudó los bombardeos aéreos y las Farc suspendieron el alto al fuego. Más tarde, en Julio del mismo año las Farc declararon otro alto al fuego unilateral e indefinido. El 29 de agosto 2016 las Farc y el gobierno colombiano declararon un alto al fuego bilateral y definitivo.

El lunes 26 de septiembre se firmó en Cartagena el acuerdo final entre el Gobierno y las Farc dando como resultado un texto oficial que contenía los seis puntos clave acordados al principio en la Agenda del Acuerdo General establecido y suscrito en el 2012. Los seis puntos acordados abordan asuntos como la Reforma Rural Integral, la participación política, la dejación de armas, drogas ilícitas, reparación de víctimas y la refrendación e implementación de los acuerdos.

Uno de los puntos que más generó debate fue el de la participación política. Para garantizar una apertura democrática que reconociera a la oposición como parte de la política del país, en el punto dos se estipuló que el que el Estado debía promover la transparencia en los procesos electorales mediante la creación de nuevos partidos políticos y, así mismo, generar una mayor participación electoral: "El ejercicio de la oposición política es pieza fundamental para la construcción de una democracia amplia, la paz con justicia social y la reconciliación nacional, aún más luego de la firma de un Acuerdo Final que abrirá espacios para que surjan nuevos partidos y movimientos políticos que requerirán garantías plenas para el ejercicio de la política". ${ }^{17}$

Una vez establecido el manuscrito se aprueba en el congreso la implementación de un plebiscito para refrendar los acuerdos. “¿Apoya el acuerdo final para terminación del conflicto y construcción de una paz estable y duradera?" La pregunta fue anunciada el 30 de agosto y a partir de ese momento se da inicio a las campañas por el "Sí" y el "No".

La campaña por el "Sí” estuvo liderada por el expresidente César Gaviria, quien aseguró que el votar en contra de los acuerdos era "votar por la guerra". Por el otro lado, Álvaro Uribe, ahora senador, lideró la campaña por el "No". Con la idea de que un plebiscito no aseguraba una participación legítima, pues darle una sola pregunta a los ciudadanos no garantizaría su aprobación en bloque y las críticas a la impunidad presente en los acuerdos, emprendió una recia campaña en contra de la refrendación de la paz que tuvo un gran eco en panorama político colombiano ${ }^{18}$.

\footnotetext{
17 Juan Manuel Santos y Timoleón Jiménez, Acuerdo Final para la Terminación del Conflicto y la Construcción de una Paz Estable y Duradera, Bogotá, 2016.

18 Juan Carlos Gómez Giraldo y Juan David Cárdenas Ruiz, “El papel de la opinión publicada en la prensa escrita colombiana antes del plebiscito del 2 de octubre de 2016" Palabra Clave, 22:1, Chía, 2019, $204-253$.
} 
El 2 de octubre del 2016 se lleva a cabo en todo el país el plebiscito para refrendar lo acordado en La Habana. Con una participación del 37\% de la población total de votantes, a las 4:00 pm el "No" gana la votación con una diferencia mínima frente al "Sí". Los departamentos que más votaron en contra de los acuerdos fueron Antioquia, Caldas y Casanare, alcanzando un 50,21\% a favor del "No", frente al 49,78\% alcanzado por el "Sí" que tuvo mayor acogida en Cundinamarca, Atlántico y Cauca ${ }^{19}$.

La incertidumbre generada por la victoria del "No" desencadenó en múltiples reacciones en líderes de cada campaña y una fuerte división en la opinión pública. Estos resultados mostraron la división de opiniones que tenía el país frente al concepto mismo de la paz. El presidente Santos fue el primero en reconocer los resultados y, así mismo, en asegurar la continuación del cese al fuego bilateral. De igual manera, el jefe negociador de las Farc Rodrigo Londoño afirmó que mantendrían la "voluntad de paz" y seguirían buscando soluciones para la terminación negociada del conflicto ${ }^{20}$.

Al día siguiente, el Centro Democrático nombra a Óscar Iván Zuluaga, Iván Duque y Carlos Holmes Trujillo como representantes de la mayoría que había rechazado los acuerdos. Entre las propuestas de reforma estaban las de prisión para aquellos que hubiesen cometido crímenes de lesa humanidad, la restricción de participación política de los guerrilleros y los límites a la reforma rural. El 7 de octubre el presidente Santos gana el Premio Nobel de paz otorgado por el comité noruego quien destacó sus esfuerzos por finalizar el conflicto armado de más de 50 años en el país.

El 3 de noviembre finalizan las negociaciones entre los promotores del "No" y el gobierno dejando como resultado un documento con 57 ejes temáticos nuevos. Se incluyeron ajustes en la justicia transicional y se aclaró el tema del enfoque de género presente en el anterior documento. El 18 de noviembre la OEA pide la inmediata implementación de los acuerdos y el 24 de ese mismo mes se firma el nuevo texto de acuerdo de paz entre el gobierno y las Farc.

En 2017 comienza la implementación de los acuerdos con la reubicación de las Farc en las 23 zonas veredales dispuestas para garantizar el cese al fuego y la dejación de armas y, así mismo, preparar el camino de los guerrilleros a la vida civil aunque con una fuerte oposición por parte de los sectores de ultraderecha en el país ${ }^{21}$

19 Registraduría Nacional del Estado Civil, "Plebiscito 2 de octubre 2016". Disponible en: https://elecciones.registraduria.gov.co/pre_plebis_2016/99PL/DPLZZZZZZZZZZZZZZZZZ_L1.htm

Revisado: 23 de agosto de 2019.

20 Yeny Serrano, "Naming the combatants of the colombian armed conflict in news broadcasts: the discursive positioning of journalists" Palabra Clave 19:1, Chía, 2016, 57-84.

${ }^{21}$ Fabio López de la Roche, "Posverdad, ideología y odio en la movilización del Centro Democrático del 1 de abril de 2017 contra el presidente Santos y el proceso de paz: análisis del registro fotográfico del evento", Sergio Roncallo-Dow, Juan David Cárdenas Ruiz y Juan Carlos Gómez Giraldo (editores), Nosotros, Colombia... Comunicación, paz y (pos)conflicto, Bogotá, Unisabana \& Ediciones EAFIT, 2019, 41-80. 


\section{Estado del arte, una aproximación}

Hemos tenido en cuenta para esta sección del artículo trabajos que abarcan el tema de análisis del discurso en torno a los diálogos de paz desde las perspectivas de los actores, medios de comunicación y Gobierno (organismos de control). Un primer y claro referente es el trabajo de Castañeda titulado Los discursos de los organismos de control sobre el actual proceso de paz en La Habana ${ }^{22}$ en el que se identifican dos objetivos. Primero, conocer el discurso que manejan los organismos de control del gobierno colombiano como: la Contraloría, la Fiscalía y la Procuraduría. Segundo, analizar estos discursos desde las variantes foucaultianas de la palabra, el gesto y el silencio.

El trabajo recopila todos los discursos de los agentes de los organismos de control a propósito del proceso de paz que se estaba llevando a cabo en La Habana. Se analizó el contenido de cada uno de los discursos, el lenguaje no verbal usado por los funcionarios y, por último, el silencio usado como discurso (el no manifestarse acerca de temas específicos en materia del Proceso de Paz).

El resultado que este estudio arrojó fue que, si bien los organismos de control se encontraban a favor del proceso, algunos de sus principales funcionarios exigían algunas medidas que favorecieran más a la sociedad. Esto se evidenció en el conteo de palabras (análisis cuantitativo) que se realizó a cada uno de los discursos analizados.

En una línea similar, Rincon Henao $^{23}$ analiza las estrategias argumentativas usó la Revista Semana a partir de las noticias para cubrir los diferentes sucesos del Proceso de Paz que, en ese momento, se llevaba a cabo en La Habana.

Para la realización de este trabajo se recolectaron todas las publicaciones informativas (144 piezas preseleccionadas de las que finalmente se analizaron 65) acerca del tema en la Revista Semana y se analizaron basándose en los esquemas argumentativos (topoi) que fueron revisados desde las diferentes estrategias comunicativas planteadas por Ruth Wodak. La noción de topoi, de origen aristotélico, es clave aquí pues hace referencia a un lugar común dentro de los discursos, la reiteración o repetición de palabras. Los resultados obtenidos mostraron que la revista Semana se encontraba a favor del proceso de paz, pues en el análisis de las estrategias argumentativas se evidenciaron algunos lugares comunes tales como: llave de la paz, crecimiento económico, responsabilidad, justicia, seguridad y relevancia histórica.

Parada Bernal ${ }^{24}$ analiza los discursos emitidos por las Farc-EP y el gobierno nacional recopilando las diferentes notas publicadas en la versión virtual El Tiempo. Este proyecto

\footnotetext{
22 Yebrail Castañeda Lozano, "Los discursos de los organismos de control sobre el actual proceso de paz en La Habana”, Revista Universidad de La Salle 63, Bogotá, 2014, 45-56.

23 Diana Marcela Rincón Henao, El discurso sobre el actual proceso de paz en la revista Semana (2012-2014), Bogotá, Univerisdad del Rosario, Periodismo y Opinión Pública, 2016.
} 
se apoya en cuatro categorías básicas: poder, comunicación, medios y discurso. El estudio se enfocó directamente en la línea editorial del medio analizado y estableció tres categorías básicas para el análisis de las notas: veracidad, información con seriedad, e independencia. Como resultado se encontró que el medio analizado cumplió con dos de las categorías asignadas, veracidad e información con seriedad, la única categoría que no fue cumplida fue la independencia, pues siempre su información aparecía como parcializada en favor de las intervenciones del gobierno.

Sánchez et al. hacen un estudio a partir de 77 boletines emitidos por las Farc- EP desde el inicio de los diálogos, llamado Análisis del discurso en torno a los diálogos de paz ${ }^{25}$. La investigación estableció los principales hallazgos con relación al análisis del discurso, teniendo como base la gramática, la retórica, los valores, las creencias y las dimensiones sociales, que incluyen las relaciones y los movimientos grupales.

Debido a los antecedentes y a la posición que tiene el grupo guerrillero, entre las principales características encontradas, se pudo determinar que dentro de los discursos se suele apelar a la victimización y a los eufemismos para justificar las acciones o mitigar los daños realizados. El uso de sinónimos para palabras como asesinatos, secuestros o violaciones son sustituidos por expresiones como 'dolores de guerra', de tal manera que genera un plano expresivo más suave que es mejor recibido por la opinión pública.

Así como se fundamentan de este recurso para describir sus propias acciones, al momento de referirse a las acciones de la contraparte, es decir, el Estado o los paramilitares, los delitos son puntualizados y enlistados de tal manera que reflejan claramente la su magnitud. Las Farc-EP se presentan como víctimas y de tal manera buscan justificar sus crímenes. Del mismo modo, a partir de dicha postura victimizante, el uso de la voz pasiva dentro de los textos refuerza los argumentos. Los autores recurren a este fragmento para ejemplificar: [...] podemos aseverar a los escasos hechos de guerra en los que se vieron involucradas unidades nuestras durante el mes de cese al fuego, corresponden a acciones de legítima defensa $[\ldots]^{26}$.

Además de que se resalta que fueron 'escasos' los hechos de guerra por parte de las Farc$\mathrm{EP}$, la oración "se vieron involucradas unidades nuestras" genera una recepción menos fuerte y de menor responsabilidad. En cuanto a la voz activa, se recurre a esta para enfatizar en las problemáticas de la contraparte y resaltar sus hechos negativos.

\footnotetext{
24 Miguel Angel Parada Bernal, “La paz en El Tiempo y el tiempo de la paz: Discursos sobre el inicio de los diálogos de paz entre la guerrilla de las FARC-EP y el gobierno nacional en el portal virtual del periódico El Tiempo", Ciudad Paz-ando, 10/09, 2015, 7:2.

25 Vanessa Sánchez Mendoza, Juan Manuel Lara Gutiérrez, Ana Carolina Rodríguez, Laura Sofía Santamaría y Jenny Lorena Carranza, Análisis del discurso en torno a los diálogos de paz, Bogotá, Univerisdad Católica de Colombia, 2017.

26 Ibid, p. 73.
} 
Por otra parte, las Farc-EP siempre se presentan como el gran vocero de los colombianos, recurriendo a las generalizaciones. En sus discursos destacan la relevancia de la participación del pueblo y de toda la responsabilidad que tiene dentro de los diálogos. A su vez, dan a entender que sus intereses son exactamente los intereses de todos los colombianos y que, así como la mayoría de ellos, también han sido víctimas y buscan el cambio.

Otra de las estrategias discursivas presentes es la de apelar a la emoción por medio de la recordación de eventos. En la medida en que se mencionan episodios de la historia donde las personas sufrieron por causas distintas a los actos de la guerrilla (como las acciones ilegales del Estado), logran reforzar sus argumentos y lograr sus objetivos. Como ocurre con las generalizaciones, por medio de este recurso, las Farc-EP buscan acercarse a pueblo.

Álvarez Romero y Suárez Suárez ${ }^{27}$ hacen un análisis del discurso de manera cuantitativa y cualitativa tanto de los discursos de las Farc-EP (Iván Márquez) como los del gobierno Nacional (Humberto de La Calle). Para la primera parte se elaboró una lista de palabras y se jerarquización de tal manera que se pudiera identificar lo más relevante de los discursos. En cuanto al gobierno, como resultado predominaron las palabras: Farc, gobierno y procesos, mientras que en los de las Farc fueron: Paz y Colombia.

Así como se muestra en la investigación, no es suficiente hacer un conteo de las palabras y determinar cuáles palabras se repiten más, sin identificar el contexto en el que se presentan. Se concluye:

El proceso lingüístico implicado en esta estrategia incluye una forma de encadenamiento lingüístico de nominación llamado supresión, ya que al nominar "Gobierno, Farc y Colombia" como actores sociales, se ocultan sujetos reconocibles a quienes se les pueden atribuir responsabilidades en lo que tiene que ver con el desarrollo del proceso. Cada organización suplanta los nombres propios de los agentes de la acción. Es así como esta estrategia permite recurrir a un saber compartido, según el cual se puede determinar qué actores están ocultos, dado que ya se conocen por la divulgación de otras noticias relacionadas con el proceso de paz"28

En cuanto al análisis cualitativo, los discursos se analizan identificando las estrategias argumentativas (figuras literarias), y las estrategias discursivas, es decir la naturalización, argumentación y legitimación. En el caso del discurso de Humberto de La Calle, se tiende a recurrir al uso de eufemismos, hipérboles y metáforas, mientras que en el de Iván Márquez, prevalecen las metáforas, hipérboles y símiles.

\footnotetext{
${ }_{27}$ Luzmila Álvarez Romero y Luz Enith Suárez Suárez, Análisis crítico del discurso en la apertura de los diálogos de paz en Colombia (2012)”, Cuadernos de Lingüística Hispánica 28, Bogotá, 2016, 69-89.

${ }^{28}$ Ibid., p. 79.
} 
Sus estrategias discursivas y argumentativas buscan la victimización y la dilución de responsabilidades, convirtiendo al gobierno como principal causante del conflicto. Los discursos están diseñados de tal manera que reafirman los valores y la ideología, y a la vez encubren las acciones del grupo guerrillero.

Respecto a los discursos del gobierno, a partir de la institucionalidad, democracia y buen plan de gobierno, se busca persuadir y lograr la aceptación sin generar disenso; se presenta el Proceso de Paz como la mejor opción y al Estado como el ente con total control para asegurar el bienestar de los colombianos.

\section{El discurso de Rodrigo Londoño Echeverri: plaza, música e ideología}

Después del Décimo Congreso de las Farc, realizado durante la última semana de agosto del 2017, donde se reunieron 1.200 ex guerrilleros en el centro de convenciones Gonzalo Jiménez de Quesada, y debatieron hasta definir tanto el nombre, como los estatutos y lineamientos de la nueva organización política fruto de los acuerdos de paz con el Gobierno. El primero de septiembre se realizó el cierre de dicho congreso en el corazón de la capital colombiana, la Plaza de Bolívar, donde después de un concierto se presentó formalmente La Fuerza Alternativa Revolucionaria del Común (Farc) como partido político legal, revitalizando a propósito el sentido de la plaza pública y su función dentro de la democracia. En este sentido cabe resaltar toda la carga simbólica que nutrió el evento y, que por supuesto, corroboró el discurso de Rodrigo Londoño como dirigente político.

Las rosas rojas jugaron un papel fundamental durante todo el evento de lanzamiento del partido político. No solo simbolizaban el logotipo de La Fuerza Alternativa Revolucionaria del Común, sino el distintivo característico de partidos socialdemócratas a nivel internacional, tales como el Partido Socialista y Obrero Español (PSOE) y el Partido Socialista de Francia. Es así como el logo del partido político emergente, la rosa roja, cuyo centro es una estrella de cinco puntas, símbolo ideológico introducido por Lenin y otros revolucionarios utilizado en emblemas y banderas comunistas se apoderó de las edificaciones que rodean la Plaza de Bolívar a través de hologramas que se proyectaron sobre las fachadas de La Catedral Primada, el Palacio de Justicia, el Capitolio y el Palacio del Liévano (sede de la alcaldía).

No solo el escenario estaba rodeado de arreglos de estas flores. Los asistentes llegaron a la plaza de forma masiva para apoyar a este actor emergente en la lucha política civil, portando consigo la rosa roja gracias a que el grupo excombatiente hizo una invitación a sus adeptos a través de su cuenta de Twitter @Farc_EPueblo para que los acompañaran en el concierto de paz y reconciliación portando esta flor en aras de legitimar su participación en la contienda electoral a la presidencia del periodo 2018-2022. 
El evento organizado por las Farc llamó mucho la atención en tanto el concierto contó con gran variedad de artistas tanto nacionales como internacionales que no sólo iban a entretener a los asistentes sino que, en la mayoría de los casos, iban a afianzar críticas cargadas con matices ideológicos encaminados al propósito de la celebración: exaltar un nuevo campo de pugna por la paz y la democracia para construir un nuevo país no desde las armas sino a partir de su ingreso a la vida política ${ }^{29}$

El público disfrutó de las presentaciones de Aries Vigoth, Totó la Momposina y Hugo Candelario en cuyas puestas en escena ritmos de diferentes partes del país creaban un puente entre la tradición y la pluralidad propiciando un ambiente de inclusión. Así, las melodías románticas del llano en conjunto con los sonidos africanos e indígenas y los nuevos sonidos del pacífico se tomaron la plaza pública apasionando a su público y arraigando con fervor aquel amor por la patria que, unida, demuestra la aspiración de lo que debe ser como nación.

Entre otros cantautores y grupos hizo presencia la Banda Bassoti. Se trata de un grupo de punk y ska italiano altamente politizado que es hoy en día uno de los grandes representantes del movimiento comunista y antiimperialista en la última década. A este grupo se le sumó Ana Tijoux, una joven chilena cuyas letras se enmarcan en el feminismo, reconociendo y exaltando los derechos de las mujeres, criticando el maltrato patriarcal y exponiendo su repudio contra el imperialismo.

Por su parte, Martín Batalla y Black Esteban, ex militantes de las Farc-EP, también hicieron parte del show. Desde sus orígenes, su música buscó imponerse como herramienta para promover una pedagogía por la paz y exponer el compromiso que debe asumir el pueblo para consagrar la nueva Colombia a través del arte ${ }^{30}$.

Estos artistas tienen en común el hecho de que hacen un llamado a la revolución, a no callar y a ser parte activa del cambio que necesita la sociedad. Además, su género es muy aceptado entre los estratos medios-bajos, abarcando a propósito a los "desheredados", aquellos a quienes las Farc busca dar vocería cerrando la gran brecha de desigualdad existente por el modelo de capitalismo salvaje que nos acoge. Es por eso que la puesta en escena, en conjunto, construyó un ambiente para transmitir un mensaje implícito de inclusión sobre el país nacional que esta nueva organización política aspira construir: "El pueblo somos nosotros, ustedes hacen parte de nosotros".

Jhonny Rivera, los Hermanos Zuleta, Ky Mani Marley y Julián Conrado también hicieron parte del show. La Fuerza Alternativa Revolucionaria del Común interactuó a través de

\footnotetext{
${ }^{29}$ Vicente Torrijos Rivera y Juan David Abella Osorio, “El comportamiento de las Farc tras la firma de los acuerdos de La Habana",_Revista Científica General José María Córdova, 16:24, Bogotá, 2018, 31-60.

30 Juan Carlos Arias Herrera, “La borradura del rostro: prácticas artísticas y el problema de la visibilidad de las víctimas”, Palabra Clave 22:2, Chía, 2019, 1-24.
} 
Twitter con los seguidores que no estuvieron presentes, brindando información detallada acerca del desarrollo del evento, además de emitir constantemente mensajes que a grandes rasgos exponían la dicotomía entre la vieja y la nueva Colombia presente en la alocución con la que las Farc buscaban mostrarse como actor político legítimo y legal. Las presentaciones musicales fueron interrumpidas para dar paso a un acto simbólico que abría las puertas a pensar una nueva Colombia, una más visible, incluyente y dispuesta a la alteridad. A través de un ritual de santería y chamanismo, cuyo objetivo era "bendecir" el surgimiento del grupo como actor activo dentro del espectro democrático, las Farc pusieron el fin de su lucha armada para dar paso a su legal y legítimo ingreso a la política y gestar a través de sus principios un camino nuevo para llegar al poder ${ }^{31}$.

La tarima se llenó de jóvenes que cargaban pancartas que decían "Bienvenidas Farc a la política" y "Construyamos democracia" mientras alentaban al resto de los asistentes con cantos y gritos que celebraban este histórico acontecimiento. El público aclamaba al jefe político de la naciente organización, Rodrigo Londoño, y las expectativas por sus palabras iban aumentando. El discurso no solo representaba el cierre del congreso y la presentación oficial de su partido político "ante el país y el mundo" — como lo expresó él mismo-, sino que marcaría el inicio de una nueva era en se abrazaba la lucha política en una demostración más de su "compromiso con la paz, con la justicia social y con la democracia".

Rodrigo Londoño subió a la tarima donde lo recibieron estos jóvenes con abrazos mientras la plaza lo aplaudía, las rosas se elevaban y diferentes banderas alusivas a la revolución se ondeaban. Timochenko llevaba en sus manos la cartilla de los acuerdos de paz a la que se le sumó un ramo de rosas que una de las jóvenes le dio. "Ser recibido por los jóvenes de nuestro país es un gran privilegio y estos acuerdos, que ya no nos pertenecen y le pertenecen al pueblo colombiano, los entrego en manos de la juventud para que los hagamos realidad." dijo Timoleón Jiménez, quien fue proseguido por la joven que, al apoderarse del micrófono, le dio las gracias en nombre de la juventud, exaltando el legado que, después de una guerra de 53 años, es entregado para construir democracia y un nuevo país.

Ahora, el evento que celebró el lanzamiento de las Farc como partido político trascendió en la agenda mediática nacional e internacional generando controversia puesto que, estando ad portas de las elecciones presidenciales del 2018, 'La Fuerza Alternativa Revolucionaria del Común' se impone en la contienda electoral como una alternativa ante la élite política que, en el ejercicio del poder, ha desamparado al pueblo. Así, el surgimiento de este nuevo partido político ha calado en los debates mediáticos, acaparando amplios apartados editoriales. Por lo anterior vale la pena ver de qué manera los medios hablaban de las Farc antes de llevarse a cabo el evento y después del mismo.

31 Janiel David Melamed-Visbal, “Participación política de las Farc-EP y apertura democrática para la construcción de la paz en Colombia: una aproximación esquemática", Izquierdas, 39, Santiago, 2018, 86-109. 
Abarcando esa primera división, medios como la BBC se dedicaron a contextualizar la guerra en Colombia: su origen, el papel de la guerrilla y sus consecuencias. CNN publicó el 31 de agosto de 2017, un día antes de la inauguración de partido, una noticia titulada "Las Farc tienen más favorabilidad que los partidos políticos colombianos" en la que destacan su imagen ante la opinión pública a propósito de una encuesta realizada por la firma Invamer Gallup según la cual la imagen negativa de las Farc había estado históricamente por encima del 90\%, sobre todo durante el gobierno del presidente Álvaro Uribe (2002-2010), alcanzando un punto máximo de $97 \%$ dos días antes de la Operación Jaque, en julio de 2008. Puede leerse más adelante: "Luego de más de 50 años en la lucha armada, tuvo una desfavorabilidad del $84 \%$, tres puntos menos que la opinión desfavorable de los partidos políticos del país, que obtuvieron un $87 \%$ en la más reciente encuesta de Gallup"32.

The New York Times tituló el 1 de septiembre: "Las Farc en el terreno político: 'Vamos a presentarnos como una verdadera alternativa de poder'" ${ }^{33}$, haciendo énfasis en su lanzamiento como partido político, legal y legítimo, para continuar con las décadas de lucha revolucionaria, sin dejar de lado los posibles obstáculos que aparecerían en la consolidación de una paz estable y duradera. En general, los medios internacionales que hablaron del evento exponen la perspectiva positiva sobre el ingreso de las Farc a la vida política. Es el caso de El País de España, que tituló "Otro paso positivo en Colombia", donde destaca que esa intromisión en la palestra política constata "el éxito indiscutible del proceso de paz en Colombia"34.

Medios locales como la revista Semana dedicaron páginas enteras a cubrir el evento y transcribir su discurso. Además de esto, el diario El Espectador presentó a Londoño como un dirigente político en su edición del 1 de septiembre de 2017, no sin antes haberse hecho el debido proceso ante la Corte Nacional Electoral. El Tiempo y Pulzo publicaron amplias galerías de fotos que narraban per se cómo avanzó la jornada. El Espectador se enfocó en la adopción del nombre y el logotipo de este actor explicando de qué manera, a partir de la resignificación de las siglas, la organización buscaba acabar con las connotaciones negativas presentes en el imaginario colectivo, pero sin dejar de lado la esencia de la lucha que continúa, aunque ahora desde otro escenario y bajo otros medios.

\footnotetext{
32 CNN en español, 31 de agosto de 2017, “Las Farc tienen más favorabilidad que los partidos políticos colombianos". Disponible en:

https://cnnespanol.cnn.com/2017/08/31/las-farc-tienen-mas-favorabilidad-que-los-partidos-politicoscolombianos/ Revisado: 25 de agosto de 2019.

33 The New York Times (es), “Las Farc en el terreno político: 'Vamos a presentarnos como una verdadera alternativa de poder'" Disponible en: https://www.nytimes.com/es/2017/09/01/farc-terreno-politicopartido-anuncio-oficial-colombia/ Revisado: 25 de agosto de 2019

34 Diario El País, “Otro paso positivo para Colombia”, España, 3 de septiembre, 2017. Disponible en: https://elpais.com/elpais/2017/09/03/opinion/1504428768_399596.html Revisado: 23 de agosto de 2019.
} 


\section{Metodología}

Este trabajo, introductorio y exploratorio, toma como corpus de análisis el discurso pronunciado por Rodrigo Londoño Echeverri con motivo del lanzamiento del partido político de las Farc. Como lo mocionábamos en la introducción, nuestra aproximación tiene dos fases que se articulan en dos tipos de aproximación: uno cualitativo y otro de corte más cuantitativo que, por ahora, se presenta como puramente exploratorio. Nuestra pieza de análisis es un artefacto de enunciación aislado, las palabras pronunciadas por Londoño del 1 de septiembre, pero lo consideraremos desde una noción más densa que es la que entraña, justamente, la idea de discurso. Como lo anota Meersohn, siguiendo de cerca de Van Dijk,

se entiende por discurso, tanto una forma específica del uso del lenguaje, como una forma específica de interacción social. Así, el discurso se interpreta como un evento comunicativo completo en una situación social. Lo que distingue el análisis de discurso de la gramática de la oración es que el análisis de discurso en la práctica se concentra específicamente en los fenómenos detrás de la oración. Obviamente, las palabras y oraciones declaradas son una parte integral del discurso, pero el discurso no se encuentra en sí mismo sólo en el conjunto de palabras y oraciones expresadas en el texto y el habla ${ }^{35}$.

Así las cosas, lo que se buscó fue intentar buscar lo no dicho e intentar una búsqueda subtextual. Consideramos que el discurso de Londoño supone un acontecimiento ${ }^{36}$ comunicativo completo en una situación social y que, como tal, tiene las características para poder ser considerado como un corpus de análisis en sí mismo.

El texto fue analizado tomando como unidades de análisis cada uno de los párrafos que lo componen según la transcripción que utilizamos. Al ser un texto relativamente corto y, en términos generales, reiterativo, logramos aislar tres grandes categorías discursivas sobre las que giraban las estrategias de enunciación de Londoño:

1. Visión de Colombia: categoría que se expande en perspectiva temporal, pasado presente y futuro.

\footnotetext{
35 Cynthia Meersohn, "Introducción a Teun Van Dijk: Análisis de Discurso”, Cinta de Moebio 24, Santiago, 2005, 288-302. p .291.

36 Sobre la idea de acontecimiento, la introducimos aquí siguiendo una pista deleuziana. El acontecimiento es la apertura de un mundo posible, la apertura de nuevos modos de modelación de lo real, en tanto formas de apertura de eso posible. El acontecimiento, justamente en tanto tal, tiene un carácter novedoso (reorganizador) e inesperado. Los acontecimientos no pueden predecirse ni producirse, pero su suceder tiene efectos de cambio sobre lo real en el sentido no solamente de la modelación del presente y el futuro sino en la producción de formas-otras de subjetividad.
} 
2. Partido político de las Farc: categoría que se expande en una doble perspectiva, como víctima y solución.

3. Acuerdo de Paz: esta categoría se divide en tres subcategorías que implican esencialmente su cumplimento e incumplimiento ( 1 y 2) así como su rol en la sociedad colombiana (3).

Este análisis se apoyó en la idea de Van Dijk ${ }^{37}$ según la cual existe un nivel pragmático en el discurso que supone un uso y una intencionalidad en los actos de habla ${ }^{38}$. De igual modo, Roncallo-Dow recuerda cómo la configuración de la realidad está dada por el modo mismo en el que esta es constituida desde la dimensión productiva del lenguaje ${ }^{39}$. En este orden de ideas, consideramos que la dimensión pragmática de Van Dijk, que supone una pregunta relacionada con el para qué es usado ese lenguaje, y qué funciona cumple una función en el contexto cultural propio de cada grupo humano, así como la dimensión productiva propuesta por Roncallo-Dow pueden ser las preguntas guía de este trabajo exploratorio. En ese sentido, y de manera más amplia, enmarcaremos la búsqueda siguiendo (como lugar de síntesis de nuestros referentes iniciales) en el marco metodológico que proponen Álvarez y Suárez:

La investigación se soporta en los enfoques cuantitativo y cualitativo, con un paradigma hermenéutico (interpretativo-crítico), ya que interpreta el lenguaje como un fenómeno social, con el fin de analizar y dar sentido al acto comunicativo que se presenta; lo que implica para el analista, no solo quedarse con el contenido explícito del discurso, sino hacer una interpretación que permita trascender e ir más allá del texto para ampliar el marco de significaciones y ver otras realidades generadas a partir del análisis ${ }^{40}$.

\section{Resultados}

Tal como lo explicitamos en los apartados anteriores, este trabajo busca hacer un análisis del discurso de Rodrigo Londoño durante el acto de ingreso a la vida política, legítima y legal, de las Farc. A continuación, presentamos el desglose de las categorías y subcategorías trabajadas y el modo en el que estas operan dentro del texto leído por el líder político. Esta primera exposición de los resultados es descriptiva y el lector encontrará el análisis en los acápites subsiguientes. Los fragmentos en negrita cursiva corresponden al

\footnotetext{
37 Teun A. Van Dijk, Estructuras y funciones del discurso. Una introducción a la lingüística del texto y a los estudios del discurso, México, Siglo XXI, 1980.

38 John Langshaw Austin, How To Do Things with Words, United Kingdom, Oxford University Press, 1962.

39 Sergio Roncallo-Dow, Más allá del espejo retrovisor. La noción de medio en Marshall McLuhan, Bogotá, Editorial Pontificia Universidad Javeriana, 2011.

40Luzmila Álvarez Romero y Luz Enith Suárez Suárez, Op Cit. p.74
} 
ser y al pasado y los fragmentos subrayados hacen parte de la dimensión prospectiva del discurso, apuntando al futuro y las soluciones.

Tabla 1. Resultados análisis del discurso

\begin{tabular}{|c|c|c|}
\hline Categoría & Subcategoría & Párrafo \\
\hline $\begin{array}{l}\text { Visión de } \\
\text { Colombia }\end{array}$ & $\begin{array}{l}\text { Colombia en } \\
\text { prospectiva }\end{array}$ & Seremos millones y millones en una Nueva Colombia. \\
\hline $\begin{array}{l}\text { Visión de } \\
\text { Colombia }\end{array}$ & $\begin{array}{c}\text { Colombia como } \\
\text { consecuencia de su } \\
\text { pasado }\end{array}$ & $\begin{array}{l}\text { Jorge Eliecer Gaitan sentenció el } 20 \text { de abril de 1944: “...en } \\
\text { Colombia hay dos países: el país político que piensa en sus } \\
\text { empleos, en su mecánica y en su poder, y el país nacional que } \\
\text { piensa en su trabajo, en su salud, en su cultura, desatendidos por } \\
\text { el país político. El país político tiene metas diferentes a las del país } \\
\text { nacional. ¡Tremendo drama en la historia de un pueblo!”. }\end{array}$ \\
\hline $\begin{array}{l}\text { Visión de } \\
\text { Colombia }\end{array}$ & $\begin{array}{l}\text { Colombia como } \\
\text { consecuencia de su } \\
\text { presente y en } \\
\text { prospectiva }\end{array}$ & $\begin{array}{c}73 \text { años después esa tragedia sigue viva. Tal y como lo sostenía el } \\
\text { caudillo, el Estado sigue representando actualmente los intereses } \\
\text { de un grupo minoritario, cuando debiera representar todas las } \\
\text { clases y defender especialmente a la que lo necesita, o sea la gran } \\
\text { mayoría de los desheredados. Proponemos a Colombia poner fin a } \\
\text { tan amarga realidad. }\end{array}$ \\
\hline $\begin{array}{l}\text { Visión sobre } \\
\text { el partido } \\
\text { político de } \\
\text { las Farc }\end{array}$ & Partido solución & $\begin{array}{c}\text { Y lo hacemos presentando ante el país y el mundo nuestro } \\
\text { partido político, FUERZA ALTERNATIVA } \\
\text { REVOLUCIONARIA DEL COMÚN Farc, en una demostración } \\
\text { más de nuestro compromiso con la paz, la democracia y la } \\
\text { justicia social para Colombia. Fueron más de } 50 \text { los años de } \\
\text { resistencia armada, llegados a su fin con la firma de los Acuerdos } \\
\text { de La Habana. Dejamos las armas para hacer política por vías } \\
\text { pacíficas y legales, queremos construir con todos y todas ustedes } \\
\text { un país diferente. }\end{array}$ \\
\hline $\begin{array}{l}\text { Visión de } \\
\text { Colombia }\end{array}$ & $\begin{array}{l}\text { Colombia en } \\
\text { prospectiva }\end{array}$ & $\begin{array}{c}\text { Un país en el que en primer término la violencia desaparezca } \\
\text { definitivamente del escenario de la política, en el que nadie sea } \\
\text { perseguido, asesinado o desaparecido por pensar diferente. Un } \\
\text { país en el que ninguno de sus habitantes se vea obligado a tomar } \\
\text { las armas para defender su vida, en el que la respuesta a la } \\
\text { protesta y la inconformidad social no sea el trato brutal del } \\
\text { ESMAD. }\end{array}$ \\
\hline $\begin{array}{l}\text { Visión de } \\
\text { Colombia }\end{array}$ & $\begin{array}{c}\text { Colombia en } \\
\text { prospectiva. Partido } \\
\underline{\text { Solución }}\end{array}$ & $\begin{array}{l}\text { Un país en el que la tolerancia y el respeto por la diferencia sean } \\
\text { la norma, en el que el diálogo y la concertación sean la forma de } \\
\text { solucionar los problemas. No queremos una sola gota más de } \\
\text { sangre por razones políticas, que ninguna madre vuelva a derramar } \\
\text { lágrimas por su hijo o hija violentados. Por ello no vacilamos para } \\
\text { extender nuestras manos en señal de perdón y reconciliación, }\end{array}$ \\
\hline
\end{tabular}




\begin{tabular}{|c|c|c|}
\hline & & $\begin{array}{c}\text { queremos una Colombia sin odios, venimos a profesar la paz y el } \\
\text { amor fraternal de compatriotas. }\end{array}$ \\
\hline $\begin{array}{l}\text { Visión sobre } \\
\text { el proceso de } \\
\text { paz }\end{array}$ & $\begin{array}{l}\begin{array}{c}\text { Cumplimiento del } \\
\text { Acuerdo por parte de } \\
\text { las Farc }\end{array} \\
\frac{\text { Incumplimiento del }}{\text { Acuerdo por parte del }} \\
\text { gobierno }\end{array}$ & $\begin{array}{l}\text { Son numerosas las demostraciones cumplidas por nosotros en } \\
\text { ese sentido. Cesamos todos los fuegos, nos ubicamos en las zonas } \\
\text { y puntos transitorios, hicimos completa dejación de las armas, } \\
\text { entregamos el inventario de nuestra economía de guerra e } \\
\text { iniciamos el proceso de entrega de todos nuestros bienes. Damos } \\
\text { ahora el paso de nuestra conversión en partido político legal. Ojalá } \\
\text { el Estado colombiano hubiera mostrado igual diligencia en el } \\
\text { cumplimiento de sus compromisos. }\end{array}$ \\
\hline $\begin{array}{c}\text { Visión sobre } \\
\text { el proceso de } \\
\text { paz/Visión } \\
\text { de Colombia }\end{array}$ & $\begin{array}{c}\text { Papel fundamental de } \\
\text { los acuerdos en la } \\
\text { sociedad colombiana. } \\
\text { Colombia en } \\
\text { prospectiva. }\end{array}$ & $\begin{array}{c}\text { No vamos a hacer aquí la defensa de nuestro alzamiento. La } \\
\text { búsqueda de la verdad del conflicto y sus víctimas estuvo en el } \\
\text { centro de los Acuerdos de La Habana, y los diversos instrumentos } \\
\text { pactados se encargarán de revelar lo realmente sucedido. No } \\
\text { tememos a la justicia. Por el contrario, clamamos por ella. Por un } \\
\text { país en el que la impunidad desaparezca para siempre, con } \\
\text { indiferencia del estrato social del responsable o de su condición } \\
\text { política. }\end{array}$ \\
\hline $\begin{array}{l}\text { Visión de } \\
\text { Colombia }\end{array}$ & $\begin{array}{c}\text { Colombia como } \\
\text { consecuencia de su } \\
\text { presente y en } \\
\text { prospectiva }\end{array}$ & $\begin{array}{l}\text { Somos conscientes de que una sociedad dividida por enormes } \\
\text { desigualdades económicas y sociales es semillero permanente de } \\
\text { conflictos e injusticias. Sabemos que unos segmentos de la } \\
\text { población colombiana detentan fortunas impensables y ostentan } \\
\text { privilegios de fábula, en tanto grandes franjas soportan } \\
\text { implacables condiciones de vida. Quizás alcanzaríamos un país } \\
\text { más humano y justo si los primeros cedieran un tanto sus } \\
\text { beneficios en provecho de los segundos. }\end{array}$ \\
\hline $\begin{array}{l}\text { Visión de } \\
\text { Colombia }\end{array}$ & $\begin{array}{c}\text { Colombia como } \\
\text { consecuencia de su } \\
\text { presente }\end{array}$ & $\begin{array}{l}\text { Nuestra reciente experiencia en Noruega nos mostró un país en } \\
\text { donde todos los ciudadanos, de acuerdo con su condición } \\
\text { económica, pagan sus impuestos y gustan de hacerlo, porque saben } \\
\text { que les serán revertidos en obras de beneficio colectivo. Por eso } \\
\text { gozan de un elevado nivel general de vida. Aquí los grandes } \\
\text { capitales pujan por la baja en su tributación, mientras se grava } \\
\text { al conjunto de la población con impuestos indirectos que } \\
\text { terminan siendo el mayor aporte del recaudo. }\end{array}$ \\
\hline $\begin{array}{l}\text { Visión de } \\
\text { Colombia }\end{array}$ & $\begin{array}{l}\text { Colombia en } \\
\text { prospectiva }\end{array}$ & $\begin{array}{c}\text { Sonamos por eso con un país en el que la transparencia y el } \\
\text { castigo ejemplar para sus violadores sean sagrados. En el que los } \\
\text { políticos sirvan realmente a la ciudadanía en vez de pensar todo } \\
\text { el tiempo en su enriquecimiento fácil. En el que no se llegue al } \\
\text { Congreso pensando en el lucro personal derivado de su posición } \\
\text { e influencia, ni a las alcaldías y gobernaciones, ni a las demás } \\
\text { corporaciones públicas o a las cortes y tribunales, como se } \\
\text { convirtió en costumbre hoy. }\end{array}$ \\
\hline $\begin{array}{l}\text { Visión de } \\
\text { Colombia }\end{array}$ & $\begin{array}{l}\text { Colombia en } \\
\text { prospectiva }\end{array}$ & $\begin{array}{c}\text { Sonamos con un país en el que en sus más de cincuenta millones } \\
\text { de hectáreas cultivables convivan en la prosperidad, la }\end{array}$ \\
\hline
\end{tabular}




\begin{tabular}{|c|c|c|}
\hline & & $\begin{array}{l}\text { solidaridad y la equidad los empresarios del campo, la economía } \\
\text { campesina y las comunidades afros e indigenas. En el que el } \\
\text { inversor o el ganadero no piensen en como incrementar sus } \\
\text { propiedades a costa de sus vecinos incomodos. En el que la } \\
\text { explotación minera no tenga que hacerse a costa de la } \\
\text { destrucción ambiental y la miseria de los pobladores. }\end{array}$ \\
\hline $\begin{array}{l}\text { Visión de } \\
\text { Colombia }\end{array}$ & $\begin{array}{l}\text { Colombia en } \\
\text { prospectiva }\end{array}$ & $\begin{array}{l}\text { Queremos un país en el que todos sus ciudadanos y ciudadanas } \\
\text { tengan acceso efectivo a la educación y salud. En el que los } \\
\text { criterios de humanidad y servicio se impongan sobre los de } \\
\text { crecimiento y ganancia. En el que los sectores estratégicos de su } \\
\text { economía estén más allá del negocio capitalista de unos cuantos } \\
\text { consorcios, un país en el que se apoye al productor nacional. }\end{array}$ \\
\hline $\begin{array}{l}\text { Visión de } \\
\text { Colombia }\end{array}$ & $\begin{array}{l}\text { Colombia en } \\
\text { prospectiva }\end{array}$ & $\begin{array}{c}\text { Un país en el que la juventud y los trabajadores gocen realmente } \\
\text { de desarrollo espiritual, en el que el deporte, la cultura, el arte y } \\
\text { la recreación eleven las mentes y oportunidades de todos. Un país } \\
\text { en donde todos tengan una vivienda digna, un lecho limpio, al } \\
\text { menos tres comidas diarias, en el que nadie esté sin trabajo y } \\
\text { menos sin una remuneración justa. }\end{array}$ \\
\hline $\begin{array}{l}\text { Visión de } \\
\text { Colombia }\end{array}$ & $\begin{array}{l}\text { Colombia en } \\
\text { prospectiva }\end{array}$ & $\begin{array}{l}\text { Un país en donde las mujeres sean reconocidas y gocen de } \\
\text { iguales derechos y oportunidades que los hombres. En el que la } \\
\text { diversidad de género y sexual no sea un estigma. En el que la } \\
\text { niñez sea el más valioso patrimonio social y por tanto se la } \\
\text { proteja y dote de las mejores oportunidades de desarrollo } \\
\text { integral. En el que la discapacidad goce del apoyo y el estímulo } \\
\text { para la superación. En el que nadie duerma en las calles y el } \\
\text { Estado asista a las personas dominadas por el vicio. }\end{array}$ \\
\hline $\begin{array}{l}\text { Visión sobre } \\
\text { el partido } \\
\text { político de } \\
\text { las Farc }\end{array}$ & Partido solución & $\begin{array}{c}\text { Ese país dejará de ser un sueño cuando millones de colombianos } \\
\text { nos empeñemos en hacerlo posible. Cuando esa inmensa mayoría } \\
\text { abstencionista se decida a actuar políticamente, cuando los } \\
\text { desengañados con el sistema político definan creer en una } \\
\text { alternativa nueva. No tenemos otra carta de presentación que } \\
\text { nuestra historia de más de medio siglo dándolo todo, hasta la } \\
\text { vida, porque nos permitieran abrir este espacio por el que puedan } \\
\text { pasar todos. }\end{array}$ \\
\hline $\begin{array}{l}\text { Visión sobre } \\
\text { partido } \\
\text { político de } \\
\text { las Farc }\end{array}$ & $\begin{array}{c}\text { Partido víctima y } \\
\text { Partido solución }\end{array}$ & $\begin{array}{c}\text { Nos precipitaron a una larga guerra al cerrarnos todos los } \\
\text { espacios políticos. Y no dejamos de luchar hasta conseguir } \\
\text { abrirlos de nuevo. Decía Gaitan que su mayor virtud era no } \\
\text { flaquear en la lucha, convertir en estimulo el obstáculo, insistir en } \\
\text { los grandes temas cada vez que fuera necesario. Creemos } \\
\text { honestamente que después de más medio siglo de empeño, nadie } \\
\text { puede dudar en nuestra persistencia de ideas, esa es la carta con } \\
\text { que llegamos a presentarnos. }\end{array}$ \\
\hline Visión sobre & Partido víctima y & Que la obra no será fácil e inmediata, lo tenemos perfectamente \\
\hline
\end{tabular}




\begin{tabular}{|c|c|c|}
\hline $\begin{array}{l}\text { partido } \\
\text { político de } \\
\text { las Farc }\end{array}$ & Partido solución & $\begin{array}{l}\text { claro. Que seremos blanco de los más sucios ataques, no lo } \\
\text { dudamos. Quien mejor que nosotros para saber que la } \\
\text { perseverancia puede vencerlo todo. Habrá que ir por etapas, no se } \\
\text { puede comenzar a construir una pirámide por su vértice. Nuestro } \\
\text { primer paso ahora es presentar a Colombia nuestro partido político, } \\
\text { su programa estratégico, nuestra propuesta de acción política. }\end{array}$ \\
\hline $\begin{array}{l}\text { Visión sobre } \\
\text { el partido } \\
\text { político de } \\
\text { las Farc }\end{array}$ & Partido solución & $\begin{array}{l}\text { Queremos y conseguiremos el reconocimiento nacional como } \\
\text { partido político legítimamente situado en el escenario nacional. } \\
\text { Impulsaremos una gran convergencia nacional, la conformación } \\
\text { futura de un movimiento de movimientos que agrupe las más } \\
\text { diversas propuestas de superación de la gran crisis nacional por } \\
\text { medios pacíficos y democráticos. Lanzamos desde ya nuestra } \\
\text { propuesta de un gobierno nacional de transición para el periodo } \\
2018-2022 \text {. }\end{array}$ \\
\hline $\begin{array}{c}\text { Visión sobre } \\
\text { el proceso de } \\
\text { paz }\end{array}$ & $\begin{array}{l}\text { Papel fundamental de } \\
\text { los acuerdos en la } \\
\text { sociedad colombiana }\end{array}$ & $\begin{array}{c}\text { Creemos firmemente que el pueblo colombiano quiere la paz y } \\
\text { estará dispuesto a defenderla como el más preciado de sus } \\
\text { derechos. Consideramos que los Acuerdos de La Habana han } \\
\text { logrado elevar una poderosa muralla ante los azuzadores de la } \\
\text { guerra y la violencia. Pero sabemos que estos no están conformes, } \\
\text { que intentan por todos los medios abrir una tronera en ese muro. } \\
\text { Apoyaremos decididamente a todo aquel que esté dispuesto a } \\
\text { blindarlo, a impedir que lo afecten. }\end{array}$ \\
\hline $\begin{array}{l}\text { Visión sobre } \\
\text { el proceso de } \\
\text { paz }\end{array}$ & $\begin{array}{l}\text { Papel fundamental de } \\
\text { los acuerdos en la } \\
\text { sociedad colombiana }\end{array}$ & $\begin{array}{l}\text { A trabajar responsable y seriamente en la cabal implementación } \\
\text { del Acuerdo Final. Estamos convencidos de que ello representará } \\
\text { un paso trascendental en la democratización de la vida nacional, } \\
\text { de que no solo elevará considerablemente la condición } \\
\text { económica y social del sector rural y representará un logro } \\
\text { significativo en la política contra las drogas ilícitas, sino que } \\
\text { posibilitará un remezón profundo en las costumbres políticas, un } \\
\text { salto adelante en la lucha social por la justicia. }\end{array}$ \\
\hline $\begin{array}{l}\text { Visión sobre } \\
\text { el partido } \\
\text { político de } \\
\text { las Farc }\end{array}$ & Partido solución & $\begin{array}{l}\text { Colombianas y colombianos: permítanme invitarlos a conocer } \\
\text { nuestro partido, a compartir la calidad humana de sus } \\
\text { integrantes, a dialogar desprevenidamente con nosotros acerca } \\
\text { de cualquier asunto de interés nacional. Allí donde haya una } \\
\text { injusticia, una afrenta, una víctima, una aspiración de orden social, } \\
\text { un proyecto de superación de las actuales condiciones, una } \\
\text { intención de paz y reconciliación, un lamento o una sonrisa, estará } \\
\text { siempre un mariano amigo, solidario, servicial, dispuesto a } \\
\text { acompañarlo en su propósito colectivo de dignificación. }\end{array}$ \\
\hline $\begin{array}{l}\text { Visión sobre } \\
\text { el partido } \\
\text { político de } \\
\text { las Farc }\end{array}$ & Partido solución & $\begin{array}{l}\text { Somos hijas e hijos de este pueblo, conocemos mejor que muchos } \\
\text { su sufrimiento y trabajos. Nuestra propuesta es unirnos por un } \\
\text { país mejor, justo, democrático, soberano y en paz. No lo } \\
\text { conseguiremos si no luchamos unidos por él, con una fe absoluta }\end{array}$ \\
\hline
\end{tabular}




\begin{tabular}{|c|c|c|}
\hline & $\begin{array}{c}\text { en conquistarlo. Hoy somos un partido que nace, en un mañana } \\
\text { no lejano seremos millones y millones en una Nueva Colombia. } \\
\text { En ella país nacional y país político se fundirán en uno solo, para } \\
\text { la felicidad de todas y todos. }\end{array}$ \\
\hline
\end{tabular}

\section{Análisis de discurso}

A partir de la lectura surgieron tres categorías macro de análisis: Visión de Colombia, visión sobre el partido político de las Farc-EP y visión sobre el proceso de paz. Cada una de estas categorías contiene sub categorías alrededor de las cuales se articula el discurso. (Ver imagen 1)

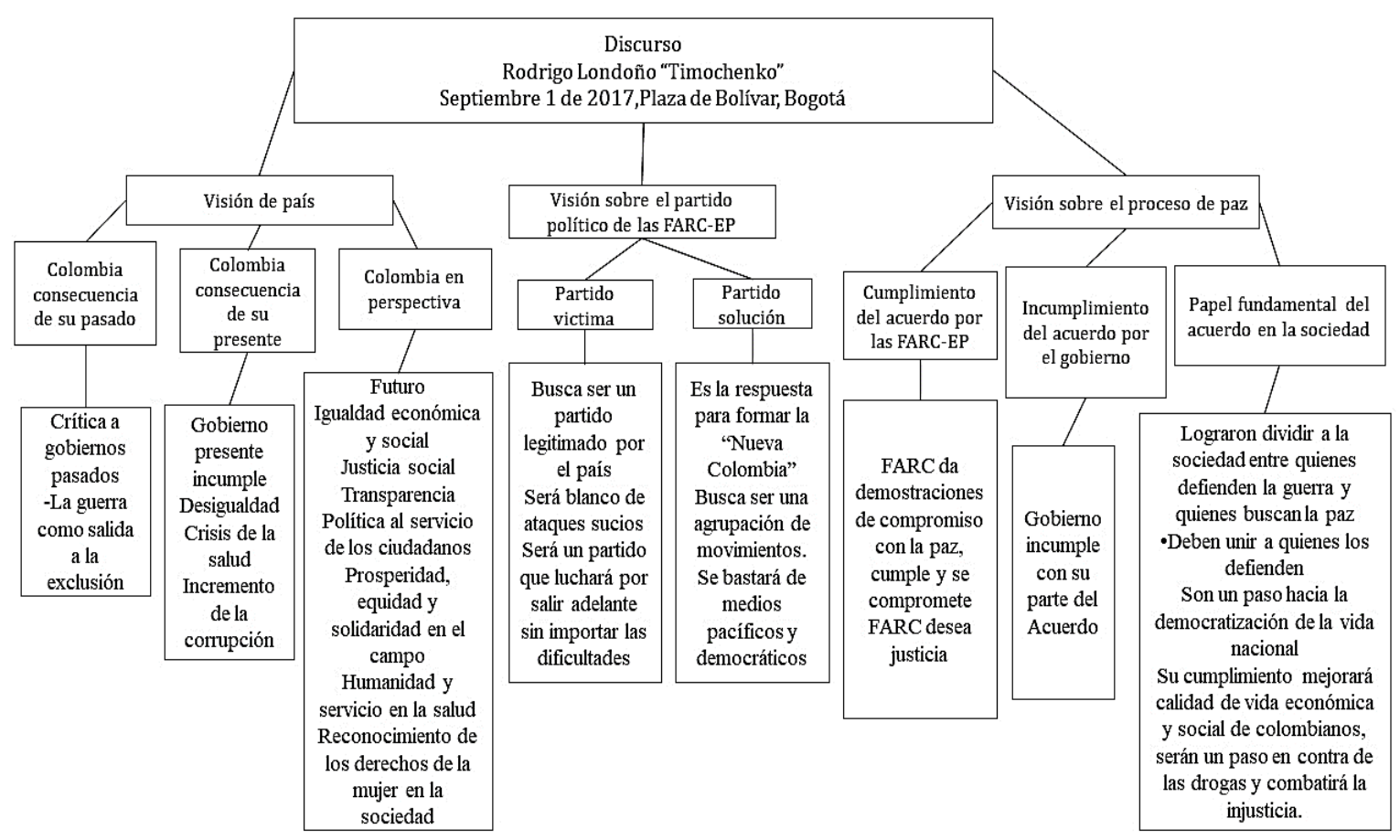

Imagen 1. Categorías del discurso. Elaboración propia.

\section{Categorías}

\section{Visión de Colombia}

En esta categoría se puede evidenciar la base del discurso ya que, desde la misma, parte el objetivo principal. Un país visto desde los espacios temporales pasado, presente y futuro, en el que se marca una situación que el mismo gobierno creó con sus acciones pasadas y 
actuales, para ello, remarca una división social con diversos conflictos (desigualdad, inseguridad y violencia), todo producto de sí mismo.

Además, con este paso, Rodrigo Londoño, construye la idea de un futuro en el que los términos "país" y "sueño" van de la mano con el objetivo de crear una identidad única, en la que esa división que tanto se señala (país político y nacional) no exista más, un futuro con cambios y ambiciones por parte de este nuevo partido político que "luchará por sus sueños".

\section{- Ser y deber ser}
A) Ser

En concreto, se divide en el "ser" de una Colombia dividida en dos países (político y nacional), que se enmarca en las acciones del gobierno pasado y del actual ("Colombia como consecuencia de su pasado y presente").

\section{B) Deber ser}

En esta parte se concentran los "sueños" que tiene el partido político Farc con el país. Es decir, un contraste de lo anteriormente mencionado; un solo país para todos sin los conflictos o productos que ellos atribuyen a los gobiernos pasados y actuales.

\section{Visión sobre el partido político de las Farc}

En las subcategorías que aquí se presentan podemos explicar ciertas partes del discurso como una "presentación" y una "explicación"; la primera tiene como objetivo dar a conocer el partido Fuerza Alternativa Revolucionaria del Común ("Partido solución") y la segunda habla de las causas de sus acciones pasadas ("Partido víctima"). Además, en estos puntos se resaltan las inclinaciones mencionadas en las subcategorías; un nuevo partido que se presenta ante la sociedad, que afirma que su lucha continúa, pero, con otros métodos ya que, ahora sí tienen participación política, que pelearán por su legitimación para ganar credibilidad como una nueva opción en contraste a la Colombia divida que ellos mencionan.

\section{- Ser}

Se habla del porqué las Farc tienen unas connotaciones negativas causa de la guerra y los medios de comunicación, por ello, sostienen que su lucha era de una forma determinada ya que no tenían espacios de participación política, por ende, resaltan la perseverancia de sus acciones en medio siglo.

- Deber ser 
Aparece aquí la lucha grupal e individual por la legitimación del partido político. Además, se habla de una lucha contra las posibles adversidades que tendrán, pero, no "cierra las puertas" a que los actores

\section{Visión sobre el proceso de paz}

La base de esta categoría es el marco del proceso de paz, aunque, tiene una idea en la que la acciones de las Farc son las debidas con respecto a lo acordado en el mismo; la intención no es ajena a la principal, las Farc actuaron de manera correcta, según lo pactado, y el gobierno no; además, recalca con frecuencia que el escenario ayudará a la democratización y a tener una Colombia en paz.

\section{- Ser}

Un proceso de paz criticado y que sembró duda, en éste, las Farc recalcan que hicieron todo lo prometido, pero, la incertidumbre, aunque enfaticen en que el gobierno no cumplió, la tienen las dos partes, por ende, el discurso también tiene un contenido que apoya la idea de que esto es un avance en la democracia.

\section{Análisis Cuantitativo}

Dentro de un contexto de construcción de paz, resultado de acuerdos establecidos en la mesa de La Habana entre el gobierno nacional en cabeza del Presidente de La República Juan Manuel Santos Calderón, el vocero del gobierno Humberto de La Calle y los principales líderes del secretariado del extinto grupo disidente Farc, se forjó el discurso del ex líder guerrillero alias Timochenko, ahora conocido como Rodrigo Londoño.

El discurso, expuesto el 1 de septiembre de 2017 en la Plaza de Bolívar, pretende dar a conocer a gran escala la visión de un país que se ha ido transformando y acomodando a los beneficios de un país político que solo piensa en el empleo, en el poder y en la mecánica para subsistir en este. A su vez, pretende dar a conocer de manera concreta la postura de una parte de la población colombiana, enmarcada y constituida como "Fuerza Alternativa Revolucionaria del Común Farc"; sumado de los condicionantes que dieron fin al proceso de Paz en La Habana.

En esta línea de ideas el discurso de Rodrigo Londoño, al estar encuadrado en tres grandes categorías, presenta un escenario propicio para la generación de un análisis cuantitativo, el cual facilite el entendimiento del peso de algunos términos dentro del contexto y la subjetividad que Londoño le impone a estos mismos. Por su parte, este análisis sirve para evaluar la intención de Londoño (ideas implícitas en el texto) desde la tensión entre el ser y el deber ser, además del trasfondo del contenido que expone en la Plaza de Bolívar. 
El análisis cuantitativo resume el total de palabras y la cantidad de párrafos y oraciones en el texto. Con base en esto, la frecuencia de palabras ofrece un punto de partida para generar una confrontación por un lado con palabras claves y por el otro con términos compuestos. Del mismo modo, la intencionalidad del texto, dependiendo de juicios de valor positivos, negativos o neutrales es de vital importancia para interpretar y valorar desde el "sentimiento", la intencionalidad global del texto.

Las palabras que más se repiten en el texto son ser, país, nacional, todos, político, partido. El concepto de "ser" está contextualizado en la globalidad del texto, haciendo referencia a cada una de las categorías y a una postura general de proyección de una Nueva Colombia. La palabra país se encuentra enmarcada principalmente en las categorías "visión de Colombia" (subcategorías: Colombia como consecuencia de su pasado y Colombia en prospectiva) y "visión sobre el partido político de las Farc" (subcategoría: partido solución). La palabra nacional se encuentra en las categorías "visión de Colombia" (subcategoría: Colombia como consecuencia de su pasado), "visión sobre el partido político de las Farc" (subcategoría: partido solución) y "visión sobre el proceso de paz" (subcategoría: papel fundamental de los acuerdos en la sociedad colombiana).

La palabra todos se encuentra en las categorías "visión de Colombia" (subcategorías: Colombia como consecuencia de su presente y Colombia en prospectiva), "visión sobre el partido político de las Farc" (subcategorías: partido solución y partido víctima) y "visión sobre el proceso de paz". La palabra político se encuentra en las categorías "visión de Colombia" (subcategorías: Colombia como consecuencia de su pasado y Colombia en prospectiva), "visión sobre el partido político de las Farc" (subcategoría: partido solución) y "visión sobre el proceso de paz". Por último, la palabra partido se encuentra en las categorías "visión sobre el partido político de las Farc" (subcategoría: partido solución) y "visión sobre el proceso de paz".

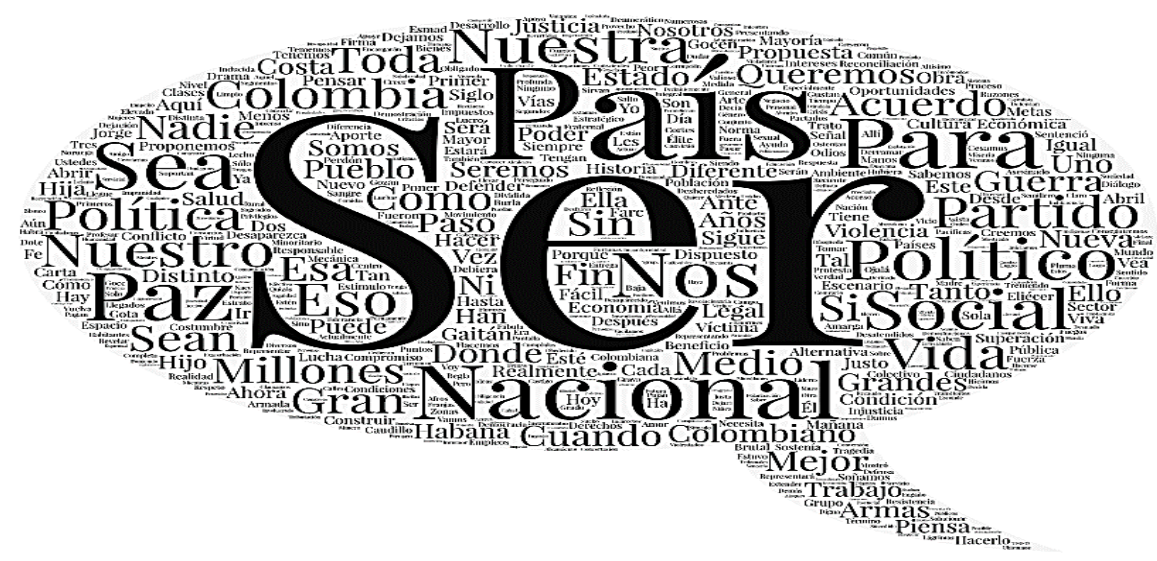

Imagen 2. Nube de palabras, análisis cuantitativo del discurso. Elaboración propia. 


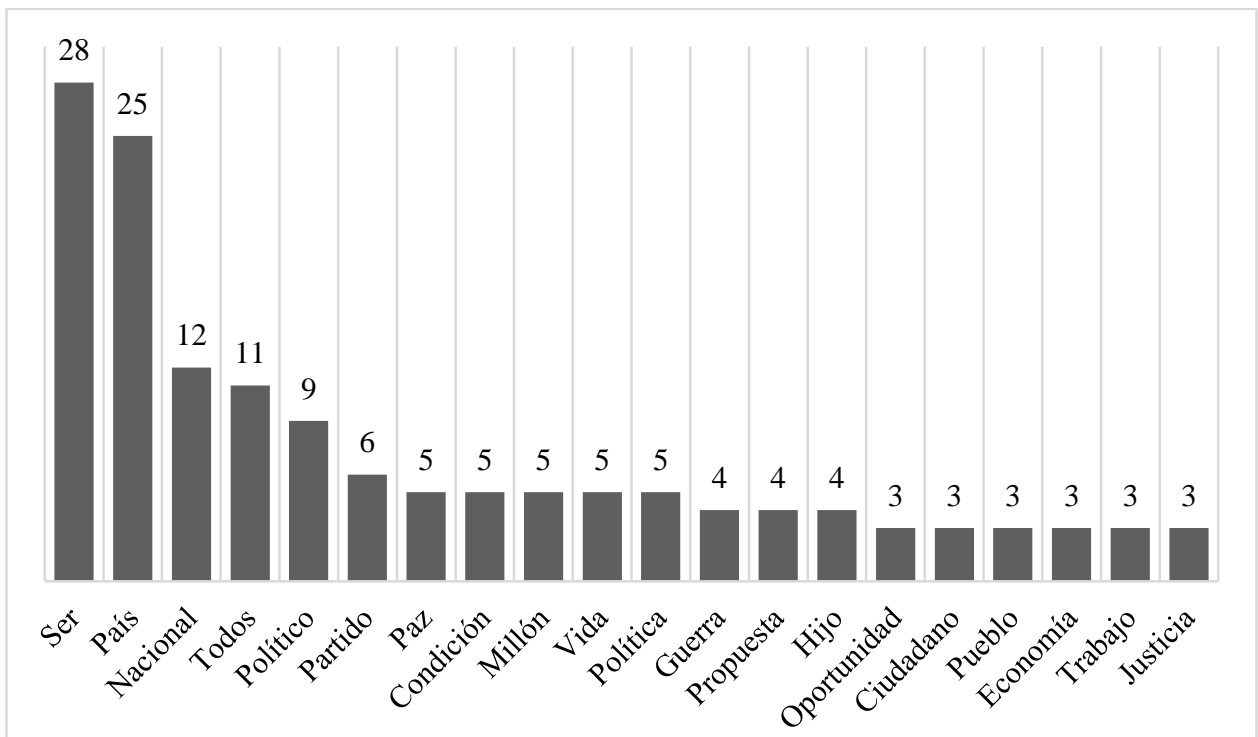

Gráfico 1. Frecuencia de palabras en el discurso (se referencian las más frecuentes). Elaboración propia

Teniendo en cuenta esta información, las principales palabras o términos clave del texto son: Colombia, Estado, acuerdos, Nueva Colombia, congreso. Si bien, hay una frecuencia mayor de otras palabras como las mencionadas previamente, estas últimas tienen una connotación mayor e integral en el texto. Al hablar de Colombia y de Nueva Colombia, el texto gira en torno a la separación y diferenciación de una Colombia situada en el tiempo (primera categoría y subcategorías). El término de Estado es utilizado en el texto desde la voz del político y caudillo Jorge Eliecer Gaitán cuando expone que "el Estado sigue representando actualmente los intereses de un grupo minoritario"; igualmente está incluido dentro del contexto de las categorías de "visión de Colombia" y "visión sobre el partido político de las Farc".

Las palabras "acuerdos" y "congreso" conllevan un vínculo cercano dentro de lo que fue el Proceso de Paz en La Habana, su resolución y la posterior reflexión de Rodrigo Londoño en el presente discurso. Los "acuerdos" al ser resultado de un proceso, entran como punto de partida en un escenario nuevo y desconocido en el que el congreso sirva de plataforma para el debate, la implantación de medidas y la solución de problemáticas, no como armazón del lucro personal.

La intencionalidad del discurso está en estrecha relación el sentimiento que puede colegirse. Es decir, qué tan positivos, neutrales o negativos son los argumentos de Londoño desde su visión y perspectiva de Colombia (país nacional vs. país político). Siguiendo esto, del texto se resumen 51 frases positivas, 24 frases negativas y 5 frases neutrales. 


\begin{tabular}{|l|l|}
\hline \multicolumn{2}{|l|}{ Sentimiento del Texto } \\
\hline Frases Positivas & 51 \\
\hline Frases Negativas & 24 \\
\hline Frases Neutrales & 5 \\
\hline Total & 80 \\
\hline
\end{tabular}

Tabla 1. Sentimiento del discurso (frecuencia). Elaboración propia.

En derivación, el discurso es mayoritariamente positivo (desde la proyección como país de Londoño) representando un 63,75\% del contenido total del discurso.

\begin{tabular}{|l|l|}
\hline \multicolumn{2}{|l|}{$\begin{array}{l}\text { Sentimiento del } \\
\text { Texto }\end{array}$} \\
\hline Positivo & $63,75 \%$ \\
\hline Negativo & $30 \%$ \\
\hline Neutral & $6,25 \%$ \\
\hline
\end{tabular}

Tabla 3. Sentimiento del discurso (\%). Elaboración propia.

\section{Otras frases relevantes:}

- Párrafo 4: "en el que nadie sea perseguido, asesinado o desaparecido por ser diferente".

- Párrafo 5: "queremos una Colombia sin odios".

- Párrafo 6: "iniciamos el proceso de entrega de todos nuestros bienes".

- Párrafo 14: "En el que los criterios de humanidad y servicio se impongan sobre los de crecimiento y ganancia".

- Párrafo 18: "nadie puede dudar de nuestra persistencia de ideas".

- Párrafo 20: "reconocimiento nacional, como partido político legítimamente situado en el escenario nacional".

\section{Puntos en consideración:}

- Cinco párrafos empiezan con verbo en plural.

- El discurso se genera en medio de un posconflicto, tras la finalidad de un proceso de paz y unos acuerdos establecidos.

- Se delega gran importancia en esta nueva etapa a los medios de comunicación.

- Ideología marxista-leninista en contra del capitalismo en contextos de desigualdad. 
- Escrito en primera persona del plural.

- Generación de una nación integrada, con tintes de exclusión.

\section{Consideraciones finales}

Este punto final que hemos abordado, el análisis cuantitativo, sirve para generar un acercamiento más profundo, en términos de intencionalidad, que un simple conteo numérico y nos permite abrir estas consideraciones finales.

El texto mismo evidencia vectores de inclusión y de exclusión exaltados en cada una de las categorías expuestas, lo cual deriva en una posible interpretación de lo que fue y ocurrió en el proceso de Paz, pero que nunca se expuso de manera concreta a la luz pública. A su vez, las palabras clave y los términos compuestos sintetizan la intención de polarización, enmarcada en un contexto de conciliación (referencia de la palabra "acuerdos"). Del mismo modo, la referencia al entorno de exclusión e inclusión, siempre está ligada en el texto a las referencias que elabora Londoño sobre las ideas "nosotros" y "otros". Es aquí donde el análisis cuantitativo trasciende el espectro numérico y genera información útil en el trasfondo de ideas que implícitamente presenta Londoño y que se pueden contextualizar en un posible subtexto.

La sección de corte cualitativo que hemos presentado más arriba muestra como un análisis de discurso nos permite entrever que, si bien Londoño busca enfatizare en la idea del dialogo y el ejercicio político de corte agonístico como solución, también presenta una continua a alusión al incumplimiento del gobierno a propósito de lo pactado en La Habana y refrendado en la firma de los acuerdos. Lo que resulta más interesante de esta alusión continua a este incumplimiento pasa, precisamente, por la aparente imposibilidad de la concreción de esa nueva Colombia que se propone como parte central del planteamiento de Londoño y que, a la postre, resultaría ser cierta si se analiza en panorama político de Colombia en el 2019 y la postura del gobierno de Iván Duque frente a lo acordado durante la administración Santos.

Finalmente, la dicotomía entre el "ser" y el "deber ser", reflejada en la concepción que expone Londoño sobre Colombia, también otorga fuentes de interpretación obtenidas de una repetición de términos que en el texto se asocian a las categorías establecidas previamente. En esta suma de ideas, una de las grandes finalidades del análisis cuantitativo, es lograr interpretar un mapa de términos y conceptos, dentro de un espacio y tiempo determinados. Esto en gran parte se desvela, en la presentación de un partido solución en pro de una nueva Colombia (nueva patria, nueva nación), incluyendo y excluyendo a quienes apoyaron el proceso de paz y quienes no. En palabras de Timochenko, los acuerdos "lograron levantar una poderosa muralla ante los azuzadores de la guerra y la violencia". 
Este punto sigue siendo problemático en la medida en que implica pensar una sociedad (re)polarizada aún en los marcos de la paz. Y es que, en efecto, uno de los grandes desgarramientos del tejido social colombiano ha tenido que ver con la dificultad para afrontar la alteridad. Esta es la piedra angular de la llamada democracia radical que ha propuesto Mouffe ${ }^{41}$ y que pretende superar la idea del enemigo (con quien tenemos una relación antagónica), reconociéndolo, más bien, como adversario (con quien tenemos una relación agónica), abocándose a la búsqueda del pluralismo y de las construcciones colectivas de ciudadanía y de instituciones democráticas que presuponen el abandono del dogma. En efecto, con un modelo agonístico y con el efectivo reconocimiento del otro como sujeto capaz-político-adversario, se hace posible pensar de manera contundente la densidad y la opacidad del tejido social. Londoño avanza en este punto en esta dirección pero en ese lugar de lo "no dicho" de su discurso las viejas polarizaciones y segmentaciones sociales parecen mantenerse e incluso hacerse más fuertes. La enunciación de ingreso de las Farc a la vida política, legítima y legal, permanece anclada a los viejos desafíos de la búsqueda de la otredad en una América Latina colonial y oligárquica que emergen en las dicotomías discursivas de Timochenko. Con todo, el llamado a la unidad y la perspectiva de una "nueva Colombia" abre una posibilidad hasta ahora inédita y permite colegir una potencia aún no actualizada (en sentido aristotélico) del discurso: la unidad y la alteridad como posibles a pesar de los desafíos que implican pensar una sociedad excluyente y conservadora como la colombiana. Quizás en ese posible radique el valor de haber hecho este estudio, en la posibilidad de pensar un mundo-otro, más justo y con posibilidades de inclusión social. Después de todo ese es el fin del ejercicio político donde lo único universal es la igualdad.

El 28 de agosto de 2019 una disidencia, liderada por Iván Márquez, decide retomar las armas. El 27 de octubre de 2019 Julián Conrado, "el cantante de las Farc", es elegido por voto popular como nuevo alcalde en Turbaco (departamento de Bolívar). La historia sigue abierta.

\section{Bibliografía}

\section{Medios de comunicación}

CNN en Español, “Las Farc tienen más favorabilidad que los partidos políticos colombianos", Estados Unidos, 31 de agosto, 2017. Disponible en: https://cnnespanol.cnn.com/2017/08/31/las-farc-tienen-mas-favorabilidad-que-lospartidos-politicos-colombianos/ Revisado: 14 de agosto de 2019.

Diario El País, “Otro paso positivo para Colombia”, España, 3 de septiembre, 2017. Disponible en: https://elpais.com/elpais/2017/09/03/opinion/1504428768_399596.html Revisado: 23 de agosto de 2019.

41 Chantal Mouffe, El retorno de lo político. Comunidad, ciudadanía y democracia radical, Barcelona, Paidós, 1999. 
Las 2 Orillas, "El día en que las Farc se tomaron la plaza de Bolívar", 02 de septiembre, 2017. Disponible en: https://www.las2orillas.co/dia-las-farc-se-tomaron-laplaza-bolivar/ Revisado: 17 de junio de 2019

The New York Times (es), “Las Farc en el terreno político: ‘Vamos a presentarnos como una verdadera alternativa de poder'” Disponible en: https://www.nytimes.com/es/2017/09/01/farc-terreno-politico-partido-anuncio-oficialcolombia/ Revisado: 25 de agosto de 2019.

\section{Bibliografía citada}

Agudelo Taborda, Jairo y Riccardi, Davide, “La cooperación internacional para la paz en Colombia: los casos de Estados Unidos y de la Unión Europea (1998-2016)", Geopolítica(s). Revista de estudios sobre espacio y poder, 10:1, Madrid, 2019, 107-134.

Álvarez Romero, Luzmila y Suárez Suárez, Luz Enith, “Análisis crítico del discurso en la apertura de los diálogos de paz en Colombia (2012)", Cuadernos de Lingüística Hispánica 28, Bogotá, 2016, 69-89.

Arias Herrera, Juan Carlos, "La borradura del rostro: prácticas artísticas y el problema de la visibilidad de las víctimas", Palabra Clave 22:2, Chía, 2019, 1-24.

Austin, John Langshaw, How To Do Things with Words, United Kingdom, Oxford University Press, 1962.

Brittain, James Jeremiah, Revolutionary Social Change in Colombia: The Origin and Direction of the Farc-EP, New York, Pluto Press, 2010.

Castañeda Lozano, Yebrail, "Los discursos de los organismos de control sobre el actual proceso de paz en La Habana", Revista Universidad de La Salle 63, Bogotá, 2014, 4556.

Dirección de Justicia, Seguridad y Gobierno (DJSG) y Dirección de Seguimiento y Evaluación de Políticas Públicas (DSEPP), "Plan Colombia: Balance de los 15 años". Disponible en:

https://sinergia.dnp.gov.co/Documentos\%20de\%20Interes/PLAN_COLOMBIA_ Boletin_180216.pdf Revisado: octubre 25 de 2019

Fairclough, Norman. Language and Power, London, Longman, 1989.

Gómez Giraldo, Juan Carlos y Cárdenas Ruiz, Juan David “El papel de la opinión publicada en la prensa escrita colombiana antes del plebiscito del 2 de octubre de 2016" Palabra Clave, 22:1, Chía, 2019, 204-253.

González Bernal, Manuel Ignacio, Roncallo-Dow, Sergio, Arango Forero, Germán, Estudiar las audiencias. Tradiciones y perspectivas, Pamplona, Eunsa, 2018.

Han, Byung-Chul, Sobre el poder, Barcelona, Herder, 2016. 2019.

Han, Byung-Chul, Hegel y el poder. Un ensayo sobre la ambilidad. Barcelona, Herder,

López de la Roche, Fabio, "Posverdad, ideología y odio en la movilización del Centro Democrático del 1 de abril de 2017 contra el presidente Santos y el proceso de paz: análisis del registro fotográfico del evento", Sergio Roncallo-Dow, Juan David Cárdenas 
Ruiz y Juan Carlos Gómez Giraldo (editores), Nosotros, Colombia... Comunicación, paz y (pos)conflicto, Bogotá, Unisabana \& Ediciones EAFIT, 2019, 41-80.

Marín Jaramillo, Jefferson, Pasados y presentes de la violencia en Colombia. Estudios sobre las comisiones de investigación (1958-2011), Bogotá, Editorial Pontificia Universidad Javeriana, 2014, 27.

Martínez Miguélez, Miguel, “Hermenéutica y análisis del discurso como método de investigación social”, PARADIGMA XXIII:12, Maracay, 2002,

Meersohn, Cynthia, "Introducción a Teun Van Dijk: Análisis de Discurso", Cinta de Moebio 24, Santiago, 2005, 288-302.

Melamed-Visbal, Janiel David, "Participación política de las Farc-EP y apertura democrática para la construcción de la paz en Colombia: una aproximación esquemática", Izquierdas, 39, Santiago, 2018, 86-109.

Mouffe, Chantal, El retorno de lo político. Comunidad, ciudadanía y democracia radical, Barcelona, Paidós, 1999.

Narváez Gómez, Leonel, “Twenty years of negotiating peace: A recipe of sticks and carrots", Ellen Babbit (editora), Human Rights and Conflict Resolution in Context: Colombia, Sierra Leone, and Northern Ireland, Syracuse (New York), 2009, 46-69.

Orjuela Escobar, Luis Javier, La sociedad colombiana en los años noventa: fragmentación, legitimidad y eficiencia, Bogotá, Universidad de Los Andes, 2005.

Parada Bernal, Miguel Angel, "La paz en El Tiempo y el tiempo de la paz: Discursos sobre el inicio de los diálogos de paz entre la guerrilla de las FARC-EP y el gobierno nacional en el portal virtual del periódico El Tiempo", Ciudad Paz-ando, 10/09, 2015, 7:2.

Penagos-Carreño, Julián, “1984 Representaciones de las Farc en la prensa: guerrilla comunista o narcoguerrilla", Palabra Clave 18:1, Chía, 2015, 12-40.

Registraduría Nacional del Estado Civil, "Plebiscito 2 de octubre 2016". Disponible en:https://elecciones.registraduria.gov.co/pre_plebis_2016/99PL/DPLZZZZZZZZZZZZ ZZZZZ_L1.htm Revisado: 23 de agosto de 2019.

Rincón Henao, Diana Marcela, El discurso sobre el actual proceso de paz en la revista Semana (2012-2014), Bogotá, Univerisdad del Rosario, Periodismo y Opinión Pública, 2016.

Roncallo-Dow, Sergio, Más allá del espejo retrovisor. La noción de medio en Marshall McLuhan, Bogotá, Editorial Pontificia Universidad Javeriana, 2011.

Ronderos, María Teresa, Guerras recicladas. Una historia periodística del paramilitarismo en Colombia, Bogotá, Aguilar, 2014.

Sánchez Mendoza, Vanessa, Lara Gutiérrez, Juan Manuel, Rodríguez, Ana Carolina, Santamaría, Laura Sofía y Carranza, Jenny Lorena, Análisis del discurso en torno a los diálogos de paz, Bogotá, Univerisdad Católica de Colombia, 2017.

Santos, Juan Manuel y Jiménez, Timoleón, Acuerdo Final para la Terminación del Conflicto y la Construcción de una Paz Estable y Duradera, Bogotá, 2016.

Santos, Juan Manuel, La batalla por la paz. El largo camino para acabar con el conflicto con la guerrilla más antigua del mundo, Bogotá, Planeta, 2019.

Serrano, Yeny, Naming the combatants of the colombian armed conflict in news broadcasts: the discursive positioning of journalists" Palabra Clave 19:1, Chía, 2016, 57-84. 
Torrijos Rivera, Vicente y Abella Osorio, Juan David, “"El comportamiento de las Farc tras la firma de los acuerdos de La Habana",_Revista Científica General José María Córdova, 16:24, Bogotá, 2018, 31-60.

Van Dijk, Teun A., Estructuras y funciones del discurso. Una introducción a la lingüística del texto y a los estudios del discurso, México, Siglo XXI, 1980. 